ARBOR CIENCIA PENSAMIENTO Y CULTURA CLXXXI 714 JULIO-AGOSTO (2005) 199-201 ISSN: 0210-1963

\title{
DON PÍO DEL RÍO HORTEGA Y VARA LÓPEZ
}

\author{
Rafael Vara Thorbeck \\ Catedrático de Cirugia y Patologia Quirúrgica de la Universidad de Granada
}

\begin{abstract}
The article describes the relationship between doctor Vara López and Pio del Rio Hortega since1921 in the laboratory of Hospital Provincial de Madrid, Instituto del Cáncer and Residencia de Estudiantes.
\end{abstract}

KEY WORDS Pio del Rio Hortega biography. Doctor Vara López. Hospital Provincial de Madrid. Instituto del Cáncer. Residencia de Estudiantes.
RESUMEN El artículo describe la relación entre el doctor Vara López y Pio del Río Hortega a partir de 1921en los laboratorios del Hospital Provincial de Madrid, el Instituto del Cáncer y la Residencia de Estudiantes.

PALABRAS CLAVE Pío del Río Hortega biografía. Doctor Vara López. Hospital Provincial de Madrid. Instituto del Cáncer. Residencia de Estudiantes.
Con motivo del homenaje que se rinde a la memoria de Don Pio del Rio Hortega, en su mansión solariega, que en su dia donase a la Universidad de Valladolid, me ha pedido su pariente lejano, Daniel Vaca Vaticón, entrañable amigo, que escriba unas cuartillas sobre la relación «cuasi parternofilial» que mantuvieron Don Pio y mi padre.

Yo no conocí a Don Pío, que hubo de exiliarse tras la Guerra Civil, y lo único que sé es que mi padre sentía un profundo respeto, devoción y cariño por su maestro, que actuó como su padrino de bodas, al no poder desplazarse nadie de la familia de mi madre para acompañarles en dicho importante evento.

Por ello me parece que lo más adecuado es dejar hablar a Vara López, copiando literalmente su "Recuerdo», publicado en Revista Española de Oncología 1965; XII; 42.

"A primeros de julio de 1921, siendo yo alumno interno en el laboratorio del hospital Provincial de Madrid, vi por primera vez al doctor Don Pío del Río Hortega, que a la sazón trabajaba alli como histopatólogo. El laboratorio de análisis clínicos, que dirigia el Doctor Mouriz, estaba situado en el último piso del Hospital, inmediatamente por debajo de la torre del reloj. Constaba de una sola habitación, muy amplia y una mesa larga, situada frente a la puerta, sobre la que habla unas altas ventanas; en su extremo izquierdo se acumulaban las orinas para sus análisis, de lo que como alumno interno estaba yo encarga- do, y en el rincón de la derecha, habla un espacio reservado, con un viejo microscopio, que ocupaba un señor todas las mañanas a las nueve; delgado, con gafas de montura de oro, atildadamente vestido, que tras ponerse una limpia bata blanca, daba comienzo a su trabajo, tiñendo cortes histológicos y montando preparaciones. De vez en cuando, se levantaba y cortaba las piezas en un microtomo de congelación, situado en el centro del laboratorio. Estudiaba minuciosamente las preparaciones histológicas en el viejo microscopio tipo Reichert, y escribia detalladamente los diagnósticos, marchándose alrededor de las doce.

Cuando yo terminaba con los análisis de orina, me acercaba tímidamente a su lado y observaba atentamente la minuciosidad con que montaba los más difíciles cortes histológicos. Un día al ver mi interés por su trabajo me enseñó una preparación al microscopio, preguntándome qué era aquello, a lo que contesté que un corte de piel, y a continuación me hizo preguntas sobre la constitución histológica de la misma y de sus glándulas y al hacerle una descripción completa, inquirió la calificación que habia obtenido con Don Santiago en histologia (fue el último curso que explicó Don Santiago en San Carlos) y al manifestarle que matrícula de honor, se interesó más por mi y todos los dias me preguntaba sobre los más diversos problemas histológicos y me enseñaba preparaciones, que yo sólo conocía a través de las descripciones de los libros y de dibujos. 
Llegó el mes de octubre, yo cesaba en el cargo del Hospital Provincial, y entonces, Don Pío me ofreció que fuera a trabajar a su laboratorio de investigación, situado en la residencia de estudiantes de la calle del Pinar, lo que acepté con gran entusiasmo, pues comprendi que de esta forma, no sólo podria ver cuanto aprendi de memoria en los libros, sino que podría estudiar histologia, y, sobre todo, porque aquel hombre me habia transmitido el gran deseo de trabajar asiduamente y comprobar por mi mismo lo que habla estudiado.

En el tercer pabellón de la residencia de estudiantes, en la planta baja que daba a una galeria abierta, existía una serie de laboratorios de investigación y de enseñanza; habia uno de quimica, otro de histología, que dirigia Calandre (cuyo becario era Sánchez Lucas), otro de bacteriología, uno mayor de fisiologia, que dirigía Negrín, y en el extremo norte, una pequeña habitación, en la existían cuatro mesas de madera, que había diseñado el maestro y que entre él y nosotros hubimos de pintar personalmente. En aquel entonces trabajábamos todas las tardes de cuatro a diez, Don Pio, Jiménez Asúa, Collado, Alberca y yo. La camaradería, el intercambio de ideas, los consejos y la enseñanza que emanaba constantemente de los hallazgos del maestro, de los que nos hacia partícipes, mostrándonos las preparaciones y explicándonos las interpretaciones que daba de la morfología que él descubria con sus métodos tintoriales, causaron en mi un gran impacto, y creo fueron decisivas en mi formación médica. Posteriormente, este pequeño laboratorio hubo de ser ligeramente ampliado, pues con los descubrimientos del maestro, cada vez existían más solicitudes de españoles y extranjeros, que deseaban trabajar con Don Pio y aprender sus métodos; por entonces, vino a trabajar Don Abelardo Gallego, que habla obtenido la Cátedra de Histología y Anatomía Patológica de la Escuela de Veterinaria y Luna, antiguo interno de Cajal. También Penfield estuvo pensionado un año al lado del maestro. Igualmente, vinieron médicos alemanes e ingleses, que pasaban temporadas en el laboratorio, para quienes habia que reservar una mesa junto al jefe. López Enriquez y Álvarez Cascos, de Madrid; Costero, de Zaragoza y Llombart, de Valencia, acudian en verano, aprovechando las vacaciones posteriormente, trabajó en este laboratorio Pérez Lista.

No han existido laboratorios de investigación más modestos que los que tuvo del Rio Hortega, precisamente cuando llevó a cabo sus trabajos fundamentales sobre la micro- glia y sobre la anatomía patológica de los tumores cerebrales; precisamente en esta época, fue cuando tuve el privilegio de trabajar a su lado. No precisó de grandes edificios ni de costosas instalaciones para hacer grandes descubrimientos. Recuerdo que era casi un problema disponer de unos cuantos animales de experimentación, por la pequeñez del local, pues tenian que estar en el mismo laboratorio en donde trabajábamos con la molestia de soportar los malos olores fue excepcional en aquellos tiempos, el poder efectuar trabajos experimentales al no disponer de mozos ni de loborantes de laboratorio. Casi fue un acontecimiento que pudiera realizarse el trabajo de Don Pío con Penfield sobre las heridas del sistema nervioso central y la participación que tenía la microglia. El laboratorio, que dependia de la Junta para Ampliación de Estudios, tenía una exigua dotación a pesar de ello se hicieron magníficos descubrimientos.

La convivencia que tuve con Don Pío durante el primer año, no se limitó al trabajo de laboratorio, sino que se extendió al circulo familiar y de sus amistades; pronto nos incorporamos a su tertulia del café, a la que acuden músicos, literatos, ensayistas, pintores, escultores, etc. y la relación de amistad y familiaridad va aumentando. El maestro se interesaba por los problemas de los que trabajamos en el laboratorio, dándonos consejos y orientaciones, no sólo en los trabajos histológicos, sino para el desarrollo de nuestra vida futura; teniendo siempre, como punto de mira, una elevada formación moral. Nos inculcó un sentido de cumplimiento del deber, despreciando la bambolla y poniendo como objetivo la observación y el estudio, que por modesto que fuese tenía que ser exacto, rígido y crítico, ajustándose a lo observado.

El maestro influyó sobre un reducido grupo de jóvenes médicos, conformando decisivamente nuestra forma de ser y hacer a lo largo de toda nuestra vida.

No olvidaremos nunca, quienes conocimos de cerca a Don Pio del Río Hortega, sus cualidades personales, que no constituyen precisamente su personalidad; las primeras son las que encontramos en el contacto diario, observando al hombre de dentro a fuera; la segunda es aquella que emana de él por sus obras, por su trabajo, por su conducta social, es decir, de fuera a dentro; las unas constituyen sus sentimientos, no siempre exteriorizados, la otra, es fruto de su inteligencia y se presenta a veces, por exigencia de la propia vida, en desacuerdo con la primera.

ARBOR CLXXXI 714 JULIO-AGOSTO (2005) 199-201 ISSN: 0210-1963 
Don Pío era un hombre delgado, de mediana estatura, muy pulcramente vestido, con unos ojos vivos y brillantes, de acerada mirada dirigida a través de sus gafas con montura de oro. Tenia un excelente carácter y era muy bondadoso. Hombre sencillo, modesto, con dotes de observación y minucioso en extremo, aprendía mirando y creaba siempre algo nuevo deducido de aquello que veía; entendimiento claro y gran sentido crítico. Tenia una voluntad firme y una constancia inquebrantable en el objeto principal de sus observaciones.

En cambio en años posteriores, cuando le nombran director del Instituto del Cáncer, le abruman los conflictos inherentes al cargo y, como hombre bondadoso, le cuesta trabajo tomar decisiones tajantes que, aunque desagradables son necesarias, y cada individuo que le plantea un problema, muchas veces nada más que por afán de molestar, le crea un estado de ansiedad, que le desvela, le desazona y le interrumpe su trabajo.

Don Pío fue un gran patriota, que puso toda su inteligencia, todo su tesón y todo su esfuerzo, en los trabajos de investigación, pensando no sólo en sus descubrimientos, sino en España. Era el prototipo de los últimos románticos: castellano viejo cien por cien, con voluntad firme y constancia inigualable en su labor. Dominaba a la perfección el castellano, y sus escritos se caracterizaban por la claridad y concisión.

En los años veinte del siglo ( $\mathrm{xx}$ ), algunos maestros, y entre ellos del Río Hortega, supieron influir sobre los jóvenes de aquella época, que tenían un gran entusiasmo no sólo de aprender sino de hacer por el simple hecho de realizar trabajos sin pensar en el beneficio económico que pudieran obtener de una forma inmediata o remota, sin otra razón que la de laborar por la Ciencia y por la Patria; eran la reminiscencia del periodo romántico. La diferencia de los jóvenes de aquella época con los de la actual, consiste en que ahora desean obtener un resultado económico positivo inmediato y entonces creíamos que, sin pensar en ello, esto llegaria por si solo, y que lo importante era trabajar. Gracias a estos maestros el trabajo que se hacía, metódico y exacto en el aspecto puramente cientifico, se generalizó a la clinica tratándose de evitar lo que en aquella época solía decirse de las comunicaciones a la Sociedad de Biología en relación con otras Sociedades Médicas: en la primera se presentaban cosas, y en las segundas, casos. Hoy se ha conseguido que algunas clínicas presenten en sus comunicaciones sobre casos, cosas, y esto se debe a este grupo de maestros que hubo en España, que con sus consejos, enseñanzas y, sobre todo, con el ejemplo de su vida, lograron el cambio que experimentó España en los últimos treinta años".

A Río Hortega le concedieron algunos honores, pocos en relación con sus méritos pero la mayor recompensa a su labor es haber alcanzado la inmortalidad por sus descubrimientos y el que en sus discípulos viva su memoria y nos guie a lo largo de toda la vida. 